\title{
Changes in heart rate as a function of an unconditional stimulus presented under varying conditions of certainty
}

ALVIN H. SHAPIRO and WALTER D. FENZ, University of Waterloo, Waterloo, Ontario, Canada

It was hypothesized that the degree of certainty about the time when a threatening event is to occur can affect heart rate in human Ss. Subjective certainty about an electric shock was varied in 54 Ss in a classical trace conditioning paradigm. Auditory cue inputs, internally (feedback) or externally (metronome) generated, were supplied to Ss. The findings were that heart-rate feedback combined with constant interstimulus intervals to shock showed the most "adaptive" change in heart-rate responses, while metronome and random shock intervals had a disruptive influence.

In the laboratory, threat may be operationally related to the uncertainty about the occurrence of a strong electric shock. Conversely, threat may be reduced by providing information relating to the certainty about the time wheri a shock is to be expected (Jones, 1966; Pervin, 1963). This study was designed to study the effect of "certainty" and "uncertainty" about the occurrence of an electric shock on heart rate.

Using a counterbalanced experimental design in which each of $54 \mathrm{Ss}$ was presented with a series of 10 trials for three discrete sessions, one group of Ss was given a constant interstimulus interval (ISI) from a signal light until shock (constant group), while another group (random group) received shock "randomly" within a comparable ISI after a signal light. Thus, all Ss received a 5-sec warning light followed by an interval and then shock.

The choice of this particular "trace conditioning" model was based on findings that the anticipatory heart-rate response of human Ss to electric shock is heart-rate deceleration in the foreperiod just preceding the presentation of the unconditional stimulus (Deane, 1961; Elliott, 1966; Obrist, 1967, 1968; Wilson \& Duerfeldt, 1967; Zeaman \& Smith, 1963). It is hypothesized that in a predictive situation (constant ISI) where expectancies can be satisfied in Ss, there is a systematic decrease in heart rate immediately prior to and during the shock presentations. In addition, three levels of input were provided to Ss: Ss received, in counterbalanced sequence, a constantly ticking metronome (as a generator of external cues), direct stethascopically amplified heart-beat feedback (internal cues), or nothing (no metronome, no feedback) during three experimental sessions.

\section{METHOD}

Fifty-four male engineering summer students were used as Ss. These Ss represented the interquartile range of scores derived from a previously administered modified version of the Taylor Manifest Anxiety Scale (Fenz \& Epstein, 1965; Fenz, 1967). All Ss were free of cardiovascular ailments, and all were paid a small sum for taking part in the experiment.

A battery-operated electronic stethascope, equipped with a high-frequency filter, was constructed in our laboratory. A crystal microphone pickup was modified to transduce heart-beat signals. The microphone was affixed by an adjustable elastic strap which fitted loosely around the S's thorax. The transduced signals fed into Koss stereophonic earphones and the amplifier had a volume control. A battery-operated variable-speed metronome with volume control was taped so that a constant pulse of 43 beats per minute fed into the Koss stereophonic earphones. A 25-W Westinghouse red-colored light was mounted on the wall directly within the S's line of vision.

Recordings were made via a Beckman Type $R$ dynograph fitted with standard Beckman couplers to record direct heart rate, and cardiotachograms, using Beckman biopotential electrodes. Shock was administered through a Hammond $800-\mathrm{V}$ ac shock generator. A Gerbrands tape programmer was used to activate the red signal light and the shock electrodes. Interstimulus intervals and intertrial intervals were presequenced on the tapes by E. The shock was $3.5 \mathrm{~mA}$ at $1 / 2 \mathrm{sec}$.

Six different program (trial) tapes were used. All six tapes were punched so that duration of "light on" to signal "light off" was $5 \mathrm{sec}$ for each separate trial. Three of the six tapes were punched so that the temporal sequence from signal "light off" to "shock" was invariantly $11 \mathrm{sec}$ for one tape, $16 \mathrm{sec}$ for another tape, and $20 \mathrm{sec}$ for the last tape. The group which received the above tapes was designated as "constant ISI." The other three tapes (designated random ISI) were so modified that the temporal sequence from signal "light off" to "shock" was variable for each discrete trial, but fell within a range of the last $10 \mathrm{sec}$ of a total $20 \mathrm{sec}$ after "light off." This was done to make the constant ISI and random ISI series comparable. For all six tapes, the intertrial interval was at least $30 \mathrm{sec}$, but no more than $39 \mathrm{sec}$.

Subjects for all experimental conditions were read exactly the same preamble informing them that the red warning light would go on, and then off, and that they would get a single shock sometime afterward. Recording electrodes were placed on the sternum (EKG) while the ground electrode was placed on the front of the inner elbow joint of the right forearm. The shock electrode was then placed on the right-hand index finger of the $S$ with the assurance that shock would only come through this particular electrode. The relevant instructions for the specific condition of testing were then read.

Following this, the prestimulus basal levels were recorded for $2 \mathrm{~min}$. At the end of each series of trials ( 10 trials per series) the $E$ informed the $S$ that there would be no more shock. No further trials were run and $2 \mathrm{~min}$ were counted off to obtain postseries basal levels.

\section{RESULTS AND DISCUSSION}

Cardiotachograms were scored for second-by-second changes for the $5 \mathrm{sec}$ between signal onset and signal offset, as well as for the $10 \mathrm{sec}$ preceding and $10 \mathrm{sec}$ following each shock. Direct heart rate was scored during $1 \mathrm{~min}$ prior to the first signal light presentation and during $1 \mathrm{~min}$ at the end of each series of 10 trials by counting the number of beats. It was found that all Ss showed a decline in heart rate from the beginning to the end of a series; the average drop, including all Ss and all series, was about five beats. This effect was found to be highly significant $[F(1,96)=66.72$, $\mathrm{p}<.0001]$. In addition, there also occurred

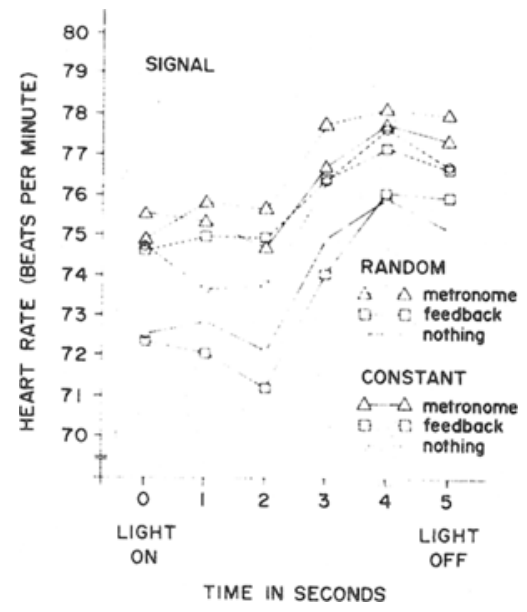

Fig. 1. Five-second heart-rate response to the signal light. The influence of treatments and conditions. 


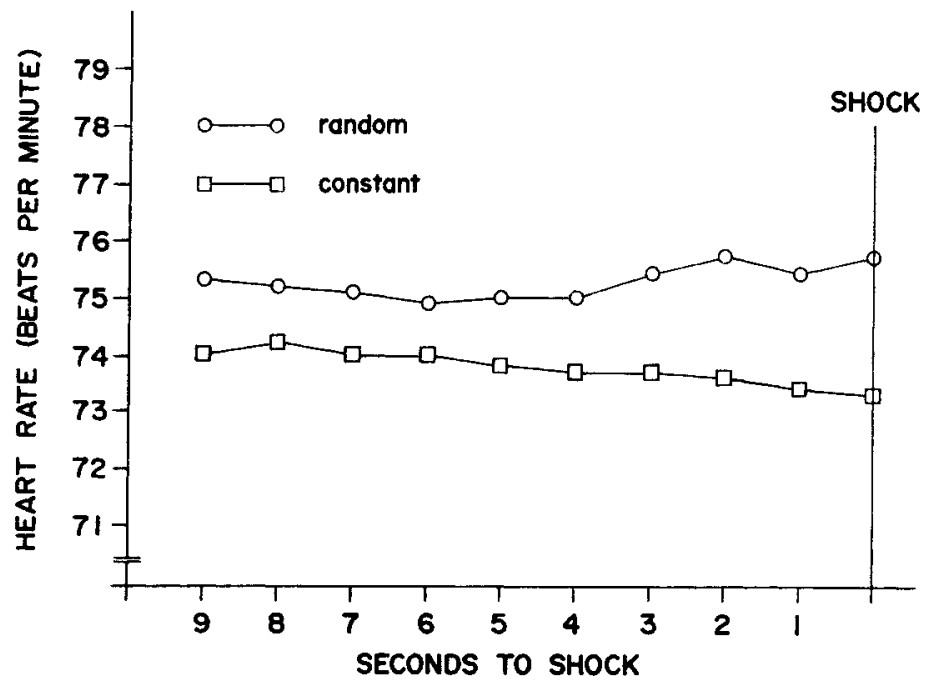

Fig. 2. Random and constant intervals to shock. a significant interaction between Groups (random vs constant) and Time (beginning to end of 10 trial series) $[F(1,96)=3.73$, $\mathrm{p}<.05]$. Heart rate was consistently higher for the random than for the constant group; the preseries basal rates differed by about 3.5 beats, while the postseries rates differed by about one beat. In view of the fact that all Ss were given the same instructions, and that a rigorous attempt was made to keep procedures uniform, the differences between the initial preseries rates for the two groups were attributed to sampling error.

\section{The "Light On" to \\ "Light Off" Interval}

The overall pattern during these $5 \mathrm{sec}$ was one of heart-rate deceleration-accelerationdeceleration. The most pronounced of these three components was heart-rate acceleration starting about $3 \mathrm{sec}$ after "light on." An analysis of variance indicated that the effect of time (changes during the $5 \mathrm{sec}$ ) was highly significant $[\mathrm{F}(1,240)=48.36$, $\mathrm{p}<.001]$.

Figure 1 illustrates the effect of cue input (metronome, feedback, and nothing) on the two groups (constant vs random); the effect of this interaction was found to be reliable $[F(10,480)=1.85, p<.04]$. Overall, the relative magnitude of the response to the signal was lower in the constant group than in the random group; however, the specific second-by-second gradients of acceleration were steeper in the constant group than in the random group. Further, the effect of the metronome resulted in elevated functions for both constant and random groups while the influence of heart-rate feedback led to a relatively large heart-rate second-by-second

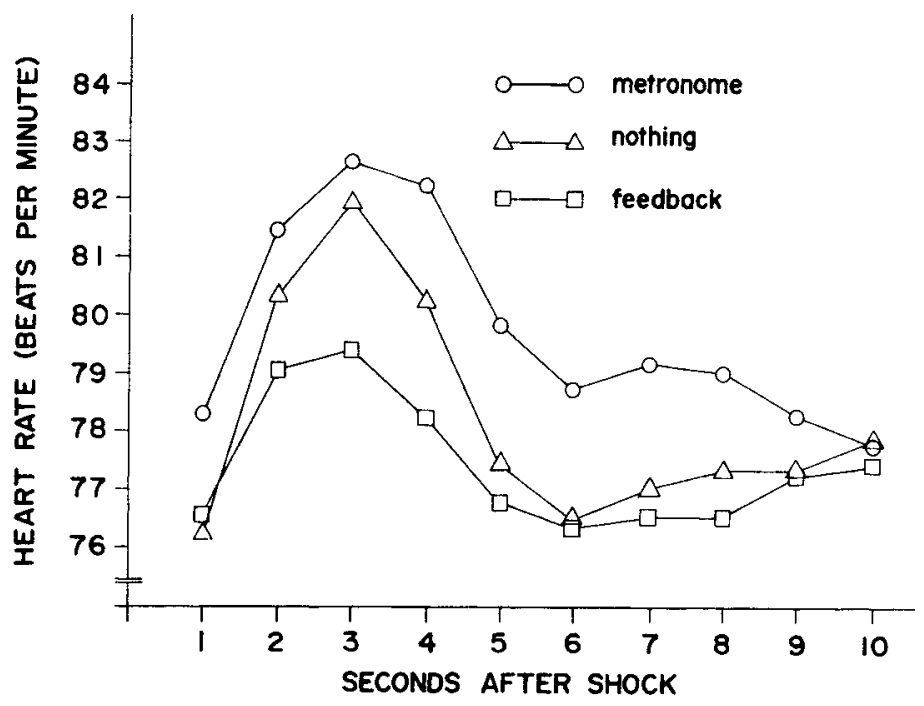

Fig. 3. Heart-rate responses after shock. The influence of cue input. acceleration in the constant treatment, and affected the steepness of the response in the random treatment to a much lesser degree.

The 10-Sec in Anticipation of Shock

Responses during the $10 \mathrm{sec}$ preceding shock are shown in Fig. 2. It may be seen that $\mathrm{Ss}$ who were able to predict the time of the shock showed a slight, but continuous, heart-rate deceleration to shock, while Ss for whom the ISI was random showed a gradual heart-rate acceleration prior to the shock $[\mathrm{F}(9,432)=2.58, \mathrm{p}<.006]$.

A breakdown of the constant ISI group indicated that the heart-rate response for Ss in the longest interval group ( $20 \mathrm{sec}$ from signal "light off') was the highest, and heart-rate responses for $S s$ in the shortest interval group (11 sec from "light off") was the lowest $[F(18,216)=1.79, p<.02]$. In addition, there was a significant effect of cue input with the constant ISI group. Ss in the nothing condition (no metronome, no feedback) and those given feedback followed very similar patterns. Ss in the metronome condition showed a much greater overall heart rate prior to shock. These cue-input interactions, however, only approached significance $[F(9,216)=1.83$, $\mathrm{p}<.06]$.

\section{The 10-Sec Following Shock}

The heart-rate responses during the $10 \mathrm{sec}$ following shock are illustrated in Fig. 3. The typical response to shock was one of acceleration for $3 \mathrm{sec}$ followed by a deceleration of $3 \mathrm{sec}$ and then a "levelling out" until Second 10. While the effects of the constant vs random ISI to shock did not result in significant heart-rate differentiation, the three input manipulations did. Figure 3 shows that heart feedback was highly reliable to "dampening" the shock effects upon the heart rate, while the metronome resulted in the greatest relative heart-rate acceleration $[\mathrm{F}(18,864)=3.51, \mathrm{p}<.0001]$.

Unexpectedly, the "order of presentation" variable proved to be generally significant in triple interactions throughout the several independent analyses when interacting with constant ISI or random ISI treatments. These interactions proved difficult to interpret. However, the single consistent influence which stood apart in affecting the heart rate was that of the metronome. It seemed important according to the treatment as to where the metronome was placed, whether the metronome was presented first, second, or third in a series. Where it was presented first, for example (Order 1), heart rate in the constant group was consistently high and heart rate in the random group was low. Where the metronome was presented last in a series (Order 2), the heart rate in the constant group was far lower across all analyses of trials than heart rate in the 
random group. Separate studies partitioning each of the conditions may pull out the contributing factors to these effects.

The main findings of this study were that "certainty" and "uncertainty" about the time to expect shock does affect the anticipatory cardiac response. Furthermore, different cue inputs can serve as a mediating variable affecting this response. Amplified cardiac cues increased the "modulation" of heart-rate responses, while external cues of less relevancy tended to interfere with the "spontaneous" heart-rate activity.

A light signalling the occurrence of a shock at some future time leads to heart-rate acceleration, perhaps as a "fear" reaction but more wikely as a general preparatory response. The steepest gradients of heart-rate acceleration in response to the signal lead reliably to gradients of deceleration in an interval prior to shock, and to the least steep gradients of acceleration in response to shock. Conversely, the least steep gradients of signal acceleration lead reliably to gradients of acceleration in an interval prior to shock, and to the greater magnitude acceleration in response to shock.

\section{REFERENCES}

DEANE, G. E. Human heart rate responses during experimentally induced anxiety. Journal of Experimental Psychology, 1961, 6, 489-493.

ELLIOTT, R. Effects of uncertainty upon the nature and advent of a noxious stimulus (shock) upon heart rate. Journal of Personality \& Social Psychology, 1966, 3, 353-356.

FENZ, W. D. Specificity in somatic response to anxiety. Perceptual \& Motor Skills, 1967, 24, 1183-1190.

FENZ, W. D., \& EPSTEIN, S. Manifest anxiety: Unifactorial or multifactorial composition? Perceptual \& Motor Skills, 1965, 20, 773-780.

JONES, A. Information deprivation in humans. In B. A. Maher (Ed.), Progress in experimental personality research. New York: Academic Press, 1966. Pp. 241-315.

OBRIST, P. Heart rate during classical conditioning in humans and dogs: Significance for psychological processes. In I. Ruttkay-Nedecky, L. Ciganek, V. Zikmund, and E. Kellerova (Eds.), Mechanisms of orienting reaction in man. Bratislava: Slovak Academy of Sciences, 1967. (Transactions of an international colloquium held in Bratislava and Smolenice, 1965, pp. 11-14, under the auspices of the Slovak Academy of Sciences.)

OBRIST, P. Heart rate and somatic-motor coupling during classical aversive conditioning in humans. Journal of Experimental Psychology, 1968, 75, 000-000.

PERVIN, L. A. The need to predict and control under conditions of threat. Journal of Personality, 1963, 31, 570-587.

WILSON, R. S., \& DUERFELDT, P. H. Cardiac responsiveness and differential conditioning. Journal of Comparative \& Physiological Psychology, 1967,63, 87-94.

ZEAMAN, D., \& SMITH, R. W. Human cardiac conditioning. In W. F. Prokasy (Ed.), Classical conditioning: $A$ symposium. New York: Appleton-Century-Crofts, 1965. Pp. 378-418. NOTE

1. This report is based on a thesis submitted by Alvin H. Shapiro in partial fulfillment of the requirements for an MA degree. It was presented at the annual meeting of the Society for Research in Psychophysiology, Washington, D.C., October
1968. The research was supported by Grant MA 2330 from the Medical Research Council of Canada to Walter D. Fenz.

\section{Differential training in multiple probability-learning and decision-making}

LOWELL M. SCHIPPER, Pennsylvania State University, University Park, Pa. 16802

Differential training in a multiple probability-learning situation, with two of the three probabilities receiving, respectively, 60-60, 60-180, 180-60, 180-180 training trials, showed nonsymmetric effects of this training when the two differentially trained probabilities were $\pi_{1}=1 / 6$ and $\pi_{3}=5 / 6 . \quad \pi_{2}=.50$ received a constant 120 training trials for all four treatments.

The purpose of this study was to investigate the use of cues which had received different amounts of training in a multiple probability learning situation in a subsequent decision-making task where combinations of cues were presented. Earlier studies (Schipper, 1967, 1966a, b) have looked at similar tasks but only with equivalent training for all cues.

\section{METHOD}

Subjects received training trials on each of three predictor (green) lights in a multiple probability learning situation. On each trial one of these lights (arranged linearly and

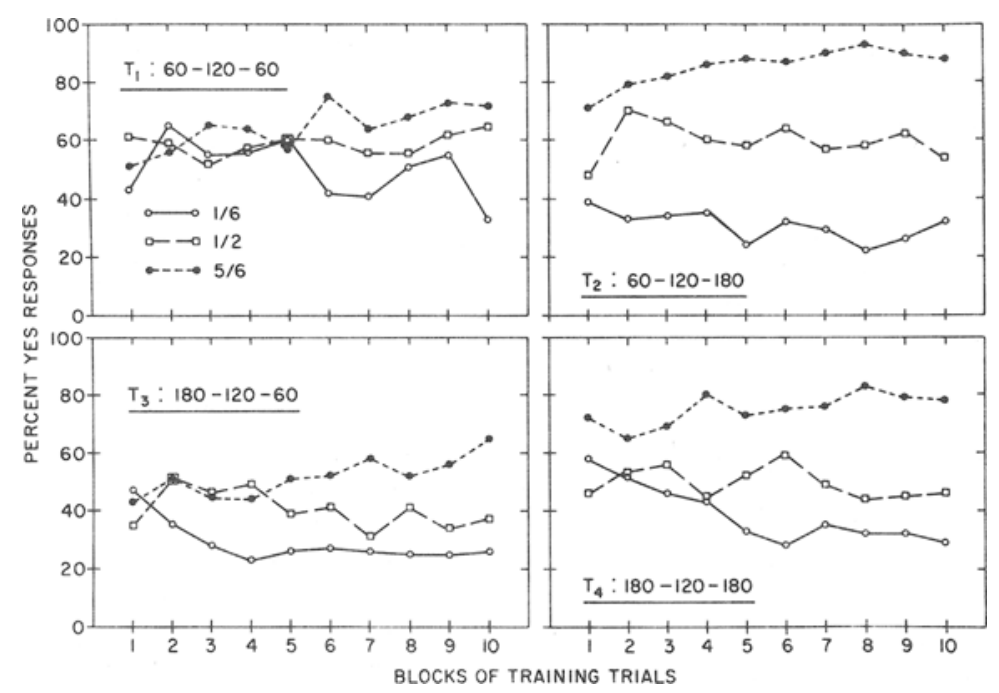

Fig. 1. Per cent yes responses on individual predictors in training. horizontally) came on for $3 \frac{1 / 2}{\mathrm{sec}}$, after which an event (red) light either came on with the green light for an additional 1 sec or did not come on with respective probabilities of $1 / 6,1 / 2$, and $5 / 6$. The intertrial interval was 2 sec.

Differential training on the three green lights was assigned according to the following schedule: $T_{1}(\mathrm{~N}=16)-\pi_{1}=1 / 6$, 60 trials; $\pi_{2}=1 / 2,120$ trials; $\pi_{3}=5 / 6,60$ trials. $T_{2}(N=18)-\pi_{1}=1 / 6,60$ trials; $\pi_{2}=1 / 2,120$ trials; $\pi_{3}=5 / 6,180$ trials. $T_{3}$ $(\mathrm{N}=17)-\pi_{1}=1 / 6,180$ trials; $\pi_{2}=1 / 2$, 120 trials; $\pi_{3}=5 / 6, \quad 60$ trials. $T_{4}$ $(N=18)-\pi_{1}=1 / 6,180$ trials; $\pi_{2}=1 / 2$, 120 trials; $\pi_{3}=5 / 6,180$ trials. The experiment can be thought of as a simple 2 by 2 factorial design with two training levels of the 1/6 light and two training levels of the 5/6 light arranged orthogonally. Training with the $1 / 2$ light is constant.

On each trial Ss predicted whether or not the red light would occur following the particular green light. Responses were made on a Digitek answer sheet using one column for "yes" responses and another column for "no" responses. All Ss were volunteers from introductory psychology at PSU and were assigned to the treatments without bias. 